\title{
Greener Golf Operations: A Comparative Case Study of Ontario Golf Courses Engaged in Environmental Sustainability Initiatives
}

\author{
Courtney Keogh ${ }^{1}$, Cheryl Mallen ${ }^{1, *}$, Chris Chard ${ }^{1} \&$ Craig Hyatt ${ }^{1}$ \\ ${ }^{1}$ Department of Sport Management, Brock University, St. Catharines, Ontario, Canada \\ *Corresponding author: Department of Sport Management, Brock University, 500 Glenridge Avenue, St. Catharines, \\ Ontario, L2S 3A1, Canada. E-mail: cmallen@brocku.ca
}

Received: May 1, 2014

Accepted: June 14, 2014 Online Published: June 30, 2014

doi:10.5430/mos.v1n2p100

URL: http://dx.doi.org/10.5430/mos.v1n2p100

\begin{abstract}
This research explored environmental sustainability (ES) initiatives at five top-ranked Ontario golf courses that were members of the Audubon Cooperative Sanctuary Program for Golf (ACSP). The Research Questions were: (1) How are golf courses adapting to safeguard the natural environment? (2) Why or why not are golf courses moving to ES? and (3) What are the arising barriers to ES in golf and how can they be overcome?

Data collection involved in-depth interviews, observations, and unobtrusive document collection for the purpose of content analysis. Data collection was framed with the dimensions of convergence by Houlihan (2012), including the motives, inputs, implementation, momentum, and impact. The dimensions were extended with the use of two constructs, including impression management or how the golf courses position their environmental messages, and message framing, or how ES was communicated to stakeholders. The environmental aspects of the examination were guided by two Standards, including The Canadian Standards Association (CSA) Requirements and Guidance for Organizers of Sustainable Events and Sustainable Sport and Event Toolkit (SSET). Data analysis involved Houlihan's dimensions of convergence extended to include impression management and message framing. Thus, RQ-1 was answered, in part, based on the following dimensions: inputs, evidence of implementation, momentum, and impact. RQ-2 was answered, in part, based on the motives, inputs, momentum, impact, and impression management. Finally, RQ-3 was answered, in part, based on inputs, momentum, impact, impressions management and message framing.
\end{abstract}

Keywords: golf; environment; sustainability; operations; communication

\section{Introduction}

Golf course development has been a global activity for over a century, with golf clubs opening in India, Ireland, Australia, Canada, South Africa, and China before the year 1900 (Ceron-Anaya, 2010). Now, there are "over 25,000 courses in diverse settings around the world" (Stoddart, 2006, p. 839). Golf's popularity continues to increase; so too do the criticisms about the negative impacts course operations have on the environment (Bartlett \& James, 2011; Chalip, 2006; Hums, 2010; Jackson, Kelly, \& Brown, 2011; Mallen \& Chard, 2011, 2012; Stoddart, 2006; Thibault, 2009; Wheeler \& Nauright, 2006; Winn \& Kirchgeorg, 2005). The purpose of this case study was to explore environmental sustainability (ES) initiatives being incorporated into the operations at top-ranked golf courses in Ontario, Canada. Through this exploration, the researchers sought to answer the following research questions:

a) How are golf courses adapting to safeguard the natural environment?

b) Why or why not are golf courses moving to ES? and

c) What are the arising barriers to ES in golf, and how can they be overcome?

Overall, the research was guided by an adaption of the dimensions of convergence (Houlihan, 2012), including the motives, inputs, implementation, momentum, and impact, as they address what golf course operators are doing and how/why they are doing it. The dimensions were extended with the use of two constructs, including impression management (Bansal \& Clelland, 2004; Bansal \& Kistruck, 2006; Fisk \& Grove, 1996; Schlenker, 1980), or how the golf courses position their environmental messages, and message framing (Cheng, Woon, \& Lynes, 2011; Levin \& 
Gaeth, 1988; Levin, Gaeth, \& Schreiber, 2002; Van de Velde, Verbeke, Popp, \& Van Huylenbroeck, 2010), or how ES was communicated to stakeholders. The environmental aspects of the examination were guided by adaptation of the standards outlined in the Canadian Standards Association (CSA) Requirements and Guidance for Organizers of Sustainable Events (CSA, 2010) and Sustainable Sport and Event Toolkit (SSET; Duffy \& Dolf, 2010). The researcher concluded that the items noted within both the CSA and SSET outline the standards for sport organizations seeking to incorporate ES initiatives into operations. As such, data collection focused specifically on the establishment and management of ES teams; explicit ES plans including, but not limited to: energy use, water conservation/use, managing consumption and waste, and so on; and communication of ES initiatives to key internal and external stakeholders. Finally, data analysis was guided by the three framing constructs noted above. Much of the data analysis focused on how ES initiatives were being communicated to key constituents and the extent to which claims of ES activities were found to be incorporated into golf course operations.

\subsection{Defining and Operationalizing Sustainability}

Sustainability is defined by the United Nations (UN) Brundtland Report (1987) as "meeting the needs of the present generation without compromising the ability of future generations to meet their own needs" (p. 1). Here, there has been a notable increase in the prevalence of ES-focused literature over the past quarter century (Etzion, 2007; Furlow, 2010; Lockett, Moon, and Visser, 2006). Given that "virtually every organizational decision generates an impact on the natural environment" (Etzion, 2007, pp. 637-638) and "business and the natural environment are inextricably linked" (Bansal \& Gao, 2006, p. 459), this should be the case. However, further calls for green initiatives have been made by international movements such as the United Nations Resolution 57/254, United Nations Educational, Scientific and Cultural Organization (UNESCO), and the United Nations Conference on Environment \& Development (UNCED; Haigh, 2005).

\subsection{ES \& Sport}

According to the United Nations Environment Programme (UNEP; 2008), sport has considerable impact on the environment. Due to advancing awareness of sport's impact on the environment (UNEP, 2008) and the broad-ranging environmental agendas (Chalip, 2006), there have been calls for an emphasis on ES in sport (Chalip, 2006; Hums, 2010; Mallen \& Chard, 2011, 2012; Thibault, 2009). Despite the numerous calls for action, however, Mallen, Stevens, and Adams (2011) found a limited number of manuscripts addressing sport ES.

Among the extant sport ES literature, there have been case analyses of the natural environment as it relates to the Olympic Games (Cantelon \& Letters, 2000; Lenskyj, 1998; Lesjø, 2000; Loland, 2006; Paquette, Stevens, \& Mallen, 2011; Preuss, 2007; Stubbs \& Slack, 2002); the ski industry (Todd \& Williams, 1996), including skiers attitudes towards the natural environment (Weiss, Norden, Hilscher, \& Vanreusel, 1998); and the online communication of ES initiatives by United States (U.S.) ski resorts (Spector, Chard, Mallen, \& Hyatt, 2012). Todd and Williams (1996) proposed the use of Environmental Management Systems (EMS) model for the ski industry that is composed of six elements, including policy, planning, procedures and controls, training and education, communication, and assessment and improvement.

Brymer, Downey, and Gray (2009) examined extreme sports and revealed that this group, generally, sought to protect the natural environment. Inoue and Kent (2012) looked at the potential for sports teams to encourage proenvironmental behaviour by sport consumers through the teams' own ES initiatives. They concluded that "a team's positive environmental practices increase consumer internalization of the team's values" (p. 428) and that "once internalization takes place, consumers are likely to show their intentions to support the team's environmental initiative and formulate their intentions to perform daily pro-environmental behavior" (p. 428). Therefore, as suggested by Inoue and Kent, consumer perceptions and willingness to adopt ES initiatives may be dependent on the sport organization demonstrating proactive behaviours in the same areas.

\subsection{ES \& Golf}

Academic literature specifically examining the golf industry exists in a limited capacity. The majority of the academic research in this field has focused on the technical aspects of golf, including equipment (Alam et al., 2011; Brouillette, 2010; Osis \& Stefanyshyn, 2012; Slater, Otto, \& Strangwood, 2010;), swing (Fedorcik, Queen, Abbey, Moorman, \& Ruch, 2012; Seaman, \& McPhee, 2012; Smith, Roberts, Wallace, \& Forrester, 2012), and the athlete (Dewar \& Kavussanu, 2011; Neumann \& Thomas, 2011; van de Pol, Kavussanu, \& Ring, 2012). Additionally, literature focused on golf tourism (Briassoulis, 2007; Gibson \& Pennington-Gray, 2005; Hennessey, MacDonald, \& MacEachern, 2008; Huertas, Gomis, Lluch, \& Torres, 2010; Humphreys, 2011; Lim \& Patterson, 2008; Markwick, 2000; Priestley, 2006; Woodside, 2009) and diversity, or lack thereof, within the sport (An \& Sage, 1992; Choi, 2010; 
Daddario \& Wigley, 2006; Jamieson, 1998; Maas \& Hasbrook, (2001); McGinnis \& Gentry, 2006; Sawyer, 1993). Additional topics include examinations of the effect of service quality and sportscape factors (Hill \& Green, 2012; Lee, Kim, Ko, \& Sagas, 2011), golf spectator experiences (Lambrecht, Kaefer, \& Ramenofsky (2009), golf marketing (Brooksbank, Garland, \& Werder, 2012; Garland, Brooksbank, \& Werber, 2011), course tee time management (Haywood-Farmer, Sharman, \& Weinbrecht, 1988), human resource management (Husin, Chelladurai, \& Musa, 2012), golf course impacts on residential property values (Nicholls \& Crompton, 2007), international trade of golf equipment (Andreff \& Andreff, 2009), PGA Tour players' decisions to enter specific tournaments (Shmanske, 2009), and finally, designing, building, operating, and maintaining courses (Bartlett \& James, 2011; Jackson, et al., 2011; Wheeler \& Nauright, 2006).

Wheeler and Nauright (2006) noted that "more people have become less tolerant of the impact that [golf] courses have" (p. 428) including the use of pesticides, water runoff, tree clearing, animal displacement, and health concerns related to golf courses. Jackson et al. looked at the incorporation of amphibian habitat in golf course designs (2011). Bartlett and James (2011) used data from existing studies on greenhouse gas (GHG) emissions in agriculture and turfgrass management to learn about GHG emissions at United Kingdom (UK) golf courses. Yet, search on the impacts of golf on the environment are still scarce; however, the call for such research is now prevalent (Chalip, 2006; Hums, 2010; Mallen \& Chard, 2011, 2012; Thibault, 2009; Winn \& Kirchgeorg, 2005).

\section{Methods}

The purpose of this comparative case study research was to explore ES initiatives at top-ranked Ontario golf courses. In-depth interviews, observations, and unobtrusive data (document) collection were conducted at five top-ranked Ontario golf courses to explore ES initiatives being incorporated into golf operations.

\subsection{Data Collection}

Case selection: The selected golf courses were in the top 50 of the Score Golf Top 100 course rankings from 2012 (Score Golf, 2012). The purposive sampling (Liamputtong, 2009) ensured the courses had similar ecosystems and weather patterns. All courses were members of the Audubon Cooperative Sanctuary Program (ACSP) at the time of data collection and therefore recognized as actively participating in ES initiatives (Audubon, 2013c). A "gatekeeper" within the golf industry made the initial contact with the superintendent at each of the eight selected golf courses, and five course superintendents agreed to participate in the research. Interviews were then set up with the other key actors and a site tour time established at each course.

Participant selection. Participant selection was guided by Nielsen and Thangadurai (2007) who identified "expert participants" as being primarily senior and middle managers with direct connection to the area of focus within the organization. Potential expert participants at each golf course were identified as the owners, representatives from the management firm, chief operating officers (COO's), general managers, directors of golf, clubhouse managers, course superintendents, and assistant superintendents.

\subsection{In-Depth Interviews}

A semi structured interview approach (Hesse-Biber \& Leavy, 2011) was used; see questions listed in the Appendix. The interview guide was framed by the dimensions of convergence, impression management, and message framing constructs. Specific environmental aspects of the interview were guided by an adaptation of the Canadian Standards Association (CSA, 2010) guidelines for organizers to host sustainable events and the Sustainable Sport and Event Toolkit (SSET; Duffy \& Dolf, 2010). The CSA and SSET are outlined below. Two pilot interviews were conducted to ensure clarity and appropriateness of interview questions.

\subsection{Observations}

Observational data supplemented in-depth interviews conducted with key actors at each course and acted as a means of verification or exploration of stated or unstated initiatives, respectively. Patton (2002) suggested that one cannot fully understand a program without having participated in/experienced it personally. Site tours were guided by one of the interview participants, and observational reports described the setting and activities observed (Patton, 2002) and were guided by an adaptation of the environmental considerations outlined in the CSA and SSET.

\subsection{Unobtrusive Data (Document) Collection for Content Analysis}

In addition to interviews and observations, Merriam (2009) acknowledged that "documents are, in fact, a ready-made source of data easily accessible to the imaginative and resourceful investigator" (p. 139). The websites and printed materials of each of the golf courses in this study were collected and later analyzed for their content, specifically 
with regards to ES initiatives. In this study specifically, printed materials included scorecards, an Audubon Recertification Package, a Club-specific Environmental Awareness brochure and Greens Committee Handbook, and the Annual Report and Environmental Policy of the corporation which owns one of the participant courses. This data collection method was intended to build on the insights the researcher gained from in-depth interviews and observations.

Canadian Standards Association (CSA). The CSA (2010) is structured to incorporate ES into the event planning, execution, and closure phases. As such, an adaptation of the CSA (2010) was used to guide the data collection methods. The eight CSA considerations (CSA, 2010) used to frame data collection methods included: getting started, planning and management, executing the event, supply chain, transportation, food and beverage catering, education and engagement, and communications.

Sustainable Sport and Event Toolkit (SSET). The SSET initiative founded by The Vancouver Organizing Committee and the International Academy of Sports Science and Technology (AISTS) aimed to incorporate sustainability initiatives into the hosting of a specific event (Duffy \& Dolf, 2010). The SSET was used to guide the data collection methods based on seven practical guidelines for sport organizations, including: commit to sustainability as a team; facilitate accessible venues and services; buy local, ethical and green where practical; operate eco-efficiently and protect sensitive areas; minimize waste to landfill (reduce, reuse, recycle); leave a positive legacy; and celebrate and share successes (p. 5).

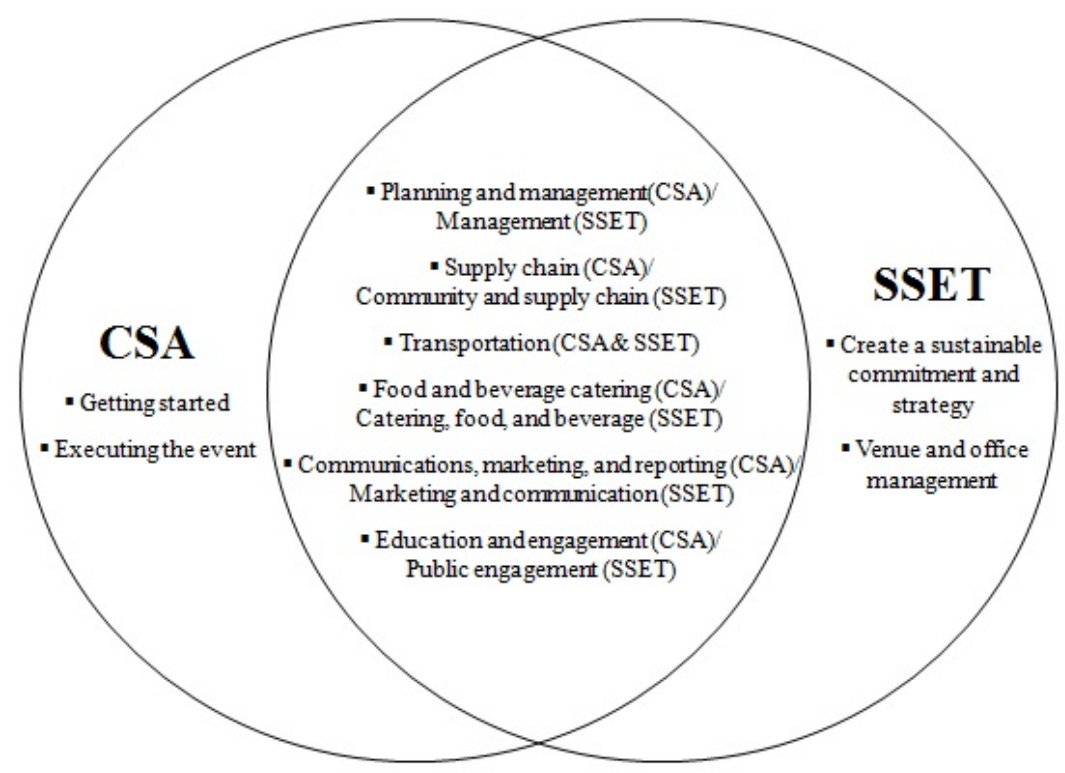

Figure 1. Consistencies in CSA and SSET Considerations

Figure 1 illustrates the considerable overlap between the CSA and SSET considerations. The researcher took this overlap as an indication that these are among the most effective ES initiatives. As such, to explore environmental aspects of dimensions of convergence, impression management, and message framing, data collection focused specifically on the establishment and management of ES teams; explicit ES plans including, but not limited to: energy use, water conservation/use, managing consumption and waste, and so on; and communication of ES initiatives to key internal and external stakeholders.

\subsection{Data Analysis}

Data analysis in this research followed a specific order for data from each course; in-depth interviews, observational notes, and documents collected for content analysis were analyzed consecutively in that order. First, analysis of in-depth interview data followed an adaptation of the process used by Brymer et al. (2009); each interview was listened to, transcribed verbatim, read, and analyzed thematically, highlighting any interesting phrases given the dimensions of convergence, impression management, and message framing constructs which framed the data collection process. Researcher notes from observational data collection followed an adaptation of Brymer et al.'s (2009) process by enacting the latter element of the process. Similar to the technique employed during observations described above, notes from interviewee responses were used to guide content analysis, allowing the researcher to 
look for key information in organizational literature to verify the ES initiatives outlined by key actors. Krippendorff's (1980) sensitizing framework, as utilized in Mallen et al. (2011) structure the content analysis, which was completed to, first, verify the ES initiatives being communicated by key actors to the researcher, and second, to examine the specific CSA and SSET considerations around communication and marketing of ES initiatives. Guided specifically by the dimensions of convergence, including impression management and message framing constructs, organizational publications were examined for key words and phrased that reflected their adherence to the abovementioned CSA and SSET guidelines, again to verify the organization's commitment to its ES plan.

For all data, written transcripts were revisited as themes across data from alternate sources became more explicit (Brymer et al., 2009). The same initial data analysis process was conducted on data collected at each subsequent golf course in this case study. Following analysis of the data from each golf course individually, comparative analysis was conducted on data sets from all courses. This process followed the analysis methodology used in an original piece of work by Cassell and Symon (2004) and adapted by Choi (2010). All collected case study data were categorized into specific "topics, key themes, or central questions for interpretation" (Choi, 2010, p. 53) and analyzed based on these categories. The analysis of topics and key themes was framed by the concepts of dimensions of convergence, impression management, and message framing. Below, each of these three analysis concepts is described.

Convergence is defined as "the tendency of societies to grow more alike, to develop similarities in structures, processes and performances" (Kerr, 1983 as cited in Houlihan, 2012, p. 112). Within this research, the "societies" are golf courses, and the growing similarities across organizations are specific ES initiatives and the overall incorporation of ES initiatives into course operations. An adaptation of Houlihan's (2012) dimensions of convergence included: motives, inputs, implementation, momentum, and impact. Communication of ES initiatives was seen as an important element of ES, as there has been a notable lack of communication within the golf industry (Calderwood, 2008). Therefore, the dimensions of convergence were extended with the constructs of impression management and message framing.

Impression management is defined as "the conscious or unconscious attempt to control the images that are real or imagined in social interactions" (Schlenker, 1980, p. 6 as cited in Fisk \& Grove, 1996, p. 7). Impression management can occur through both interpersonal exchanges (e.g., face-to-face interaction between the buyer and seller) and general marketing (e.g., corporate image advertising, organizational publications, etc.; Fisk \& Grove, 1996). It is possible that, through impression management, an organization can "create and sustain a desired image" (Fisk \& Grove, 1996, p. 9) with various marketing and promotional efforts. Bansal and Kistruck (2006) note that "general [ES] statements should be accompanied by specific facts that are either easy to navigate or few in number, but still powerful enough to be meaningful to the reader" (p. 178). The impression management construct allowed the researchers to explore how golf course operators position their environmental messages.

Message framing is the extent to which "favorable or unfavorable associations with positively or negatively phrased attribute labels mediate the evaluation of consumer goods" (Levin, 1987 as cited in Levin \& Gaeth, 1988, p. 374). Message framing "presupposes that the way an audience responds to a particular message can depend on how the message is composed" (Cheng et al., 2011, p. 49). In general, messages are framed either positively (i.e., focused on gains) or negatively (i.e., focused on losses; Van de Velde, et al., 2010). Levin et al. (2002) described three typologies of message framing:

a) attribute message framing sees the evaluation of an object or event being more favorable if the message is framed positively rather than negatively;

b) goal message framing is persuasive in that it either emphasizes the positive consequence of performing an act or the negative consequence of not performing that same act; and

c) risky choice framing sees the willingness of one to take a risk dependent on whether the results are positively or negatively framed.

Levin et al. concluded that both attribute and risky choice framing saw more favorable results when the message was framed positively, while no significant conclusions could be drawn about goal framing. The message framing construct allowed the researchers to explore how ES was communicated to stakeholders.

\section{Findings and Discussion}

The purpose of this case study was to explore environmental sustainability (ES) initiatives at top-ranked Ontario, 
Canada golf courses. The results are presented within the three analytic categories: dimension of convergence, impression management, and message framing. To protect participant identity, each course $(=\mathrm{C})$ and each participant (= P) was assigned a number (e.g., C1,P1; C1,P2; C2,P1; etc.).

\subsection{Dimensions of Convergence: Motives}

Motives referred to "factors that prompted the aspirations and the factors which influenced the extent (amount and duration) of resource allocation" (Houlihan, 2012, p. 113). Across the courses under examination, common motives included Corporate Social Responsibility (CSR), ethical obligation, and personal commitments to the environment by leaders within the organization, along with regulations and/or legislation. Across all five courses, CSR was noted as a prime motivation for implementing ES. Two superintendents stated that Audubon membership was motivated, at least in part, by the desire to positively impact the environment in which the course operates:"... It's doing our part and making sure that we're protecting the environment that we're using for our product, right?" (C5,P1); and "the Club recognizes it as a priority ... to be part of a program that demonstrates the club's commitment to preserving the environment that we're a part of" (C3,P1). Additionally, C1,P1 and C3,P2 spoke about improving the image of the club for members and employees. Further, the ethical obligation was noted as a motive for ES initiatives. Interviewees indicated that ACSP membership and overall environmental consciousness is "the right thing to do" (C2,P1 and C5,P1) and is a part of the club's "due diligence" (C5,P1 and C4,D5).

At three courses, a personal commitment to the environment by individual leaders within each organization was also a motivating factor. In two cases, the course superintendent was noted as the leader of the initiative to join the ACSP, either because of previous successes with the program at another course (C2,P1) or the simple belief that membership was important to the future operations of the Club $(\mathrm{C} 4, \mathrm{P} 1)$. The personal commitment by individual leaders within the clubs transcended the initial motivation to influence overall decision making and staff involvement with respect to ES initiatives (C3,P3 and C4,P2).

Finally, regulations/legislation was a motive for joining the ACSP and engaging in ES; however, the prevalence of this motive was less than expected, as it was noted at only two courses. Regulations, particularly around water usage $(\mathrm{C} 1, \mathrm{P} 2)$ and integrated pest management (IPM; C5,P2) motivated courses to improve environmental awareness and ES initiatives. C1,P1 indicated that there was a "move to get onside with all the regulations ... to make sure that we're in compliance. That we're not exposing the club to possible fines." However, it was noted by this research team that regulations/legislation are often bare minimum requirements.

\subsection{Dimensions of Convergence: Inputs}

Inputs, or the tangible and intangible contributions, including "finance, administrative capacity, expertise, evidence and ideas" (Houlihan, 2012, p. 113) contribute to policy design and aid implementation. The identified inputs aid in the generation and execution of ES initiatives at golf courses. It was found that the most prominent input was expertise, with both internal and external sources of expertise being recognized. A Club-wide philosophy on environmental consciousness was also identified and considered an intangible input. In contrast, tangible inputs included environmental plans (i.e., Audubon, IPM, and club-specific forestry management and Greens committee plans) and money.

Despite the lack of formal ES teams and leadership, it was established that internal expertise from specific employees and/or members was among the most prevalent inputs that contributed to establishing and implementing ES initiatives. In all cases, the course superintendent was identified as a key individual who provided internal expertise. The Superintendents were identified either as having instigated the move to become Audubon certified (C1,P1 and C2,P1) or as having encouraged further ES initiatives based on past work experience with ACSP courses (C3,P1; C4,P1; C4,P2; and C5,P1). The expertise Superintendents provided was held in high regard; for instance: "the guys who worked for [a particular course superintendent] had a marvellous advantage to be part of the work force ... It's experience he could not have gotten in school" (C1,P1). The expertise included, but was not limited to, recycling programs, wildlife inventories, and an overall proactive ES approach towards new projects at the clubs. Further, with respect to external expertise as an input, C1 and C4 both used external agencies to guide the major ES projects the clubs undertook; C1,P2 spoke about the club's own arborist and other consultants that were used in building a state-of-the-art water reservoir; and C4 brought in two "experts" from the United States Golf Association (USGA) to guide the course through heavy tree removal to increase airflow and sunlight to six problematic greens (C4,P1 and C4,P2). Only C5 had access to an environmental policy manager employed by the organization (C5,P1).

Another intangible input noted at three of the five courses (C3, C4, and C5) was a company-wide philosophy on environmental consciousness. Courses were found not to have a stated and/or formal definition of ES that guided 
operations. Participants, however, noted that an overall "green philosophy" throughout the clubs contributed to ES initiatives striving for "zero impact" and living "harmoniously" with nature (C5,P4). Finally, C3,P1 expressed this overall green philosophy as an "essentially core value in the way we think ... that sustainability philosophy does go through the train of thought of everybody at the club" (C3,P1).

With respect to tangible inputs, environmental plans (i.e., Audubon, IPM, and club-specific forestry management and greens committee plans) were found to be customary across all five courses. As ACSP certified courses, all five clubs have access to and derive guidance from the Audubon Certification Handbook (Audubon International, 2004). This handbook is used to guide meeting certification and recertification requirements by outlining six sections: environmental planning, wildlife and habitat management, chemical use reduction and safety, water conservation, water quality management, and outreach and education. C4,P1 and C4,P2 spoke about the club's Green Committee Handbook that "is a diligent framework designed to avoid an ad hoc approach to environmental management" (C4,D5) that outlines eight policy objectives (e.g., pesticide use, creek-side mowing, grass clipping composting, and so on) and the rationale behind each. Interestingly, this document was not mentioned by the club's general manager or superintendent when asked about an ES plan.

Finally, as suggested by Houlihan (2012), finances/money were identified as inputs. C4,P2 spoke primarily about obtaining environmental credits from the government and funding from external agencies to complete ES initiatives, though he also acknowledged the importance of member approval for spending at the private club. Member input regarding project funding was also discussed by another superintendent (C1,P2), who provided an anecdote to explain, "if you think about it, everybody [members] is conscious of the environment but ... they're not. Not a lot of them care ... 'Let's just do it. BUT, is this going to cost me anything?"' C1's Multi-million dollar water reservoir project was approved by members, but only after much convincing of its necessity and long-term benefits by the course superintendent $(\mathrm{C} 1, \mathrm{P} 1)$. All of the courses visited for this research were private and therefore rely on member approval for spending. Though money is a necessary input for ES initiatives, as noted above, alternate funding is desired, as members are not always willing to approve spending for certain projects. As such, the importance of being "cost effective" $(\mathrm{C} 1, \mathrm{P} 1)$ and achieving sustainability from a financial perspective $(\mathrm{C} 3, \mathrm{P} 1)$ is crucial to ensure money is best utilized as an input toward ES initiatives.

Overall, it was generally found that, while there was no indication that a formalized ES leader, team, or plan existed (as was suggested as necessary by both the CSA and SSET), there was evidence that clubs utilized alternative, less formalized inputs to aid in the creation and implementation of ES initiatives. Internal and external expertise, along with employee involvement, were the most common intangible inputs; these inputs, arguably, provide the same direction and support as a formalized ES leader or team. Likewise, the often-identified tangible input labeled as environmental plans (i.e., Audubon, IPM, and club-specific forestry management and greens committee plans) could provide similar structure to ES initiatives as a formalized ES plan. However, these plans appeared to be general guidelines for many golf courses (i.e., Audubon, IPM) and/or project specific (i.e., forestry management and greens committee plans). Therefore, it was found that there is still a place for course-specific, multi-faceted ES plan development. Finally, as financial resources can be scarce, course operators must pursue alternate forms of funding and increase financial efficiency in the ES plans.

\subsection{Dimensions of Convergence: Implementation}

Implementation referred to "the selection of specific instruments and delivery mechanisms" (Houlihan, 2012, Table 1, p. 113). In terms of golf course ES initiatives, these instruments were shown to most often include specific projects and/or programs around recycling, water, energy, and trees. When discussing implementation, however, it is important to distinguish between "policy as action" and "policy as activity." While both types of instruments involve commitment of resources, "action" is tied to positive impacts on the problem being addressed (i.e., ES), whereas 'activity' remains stated, but unexecuted (Houlihan, 2012). As such, the instruments for implementing ES initiatives at golf courses can be categorized as both "policy as action" and "policy as activity," depending on the stage of their execution and/or level of commitment to the initiative.

The first and most prevalent implementation instrument for ES initiatives was recycling, as identified by participants' at all five courses. Basic recycling of glass, plastic, metals, paper, and cardboard was both mentioned in interviews and confirmed during site tours at each course. Sorting materials was noted as an important aspect of these recycling programs and C4,P2 and C5,P1 described the process of staff separating materials from on-course bins for garbage and recycling. Within the clubhouse, the use of recycling totes in various departments, including the kitchen and office spaces, was mentioned (C3,P1 and C5,P1) and observed during site tours, indicating that separation of materials for recycling was utilized throughout these properties. The ubiquitous nature of recycling programs was not 
only noted by the researcher during data collection but was also acknowledged as "we recycle in the standard way that probably everybody does now" (C4, P1); and "just your standard items ... cans and bottles and stuff like that, when we're cleaning the golf carts ... that's fairly standard practice at the courses I've been at" (C3,P3).

The second most identified implementation instrument involved water conservation and management at courses, both externally (i.e., on the golf course) and internally (i.e., in the clubhouse). External water programs typically focused on irrigation systems. Two courses in particular had systems in place to capture water naturally rather than drawing directly from rivers/lakes. One course was "off the water grid" with its 5-hectare water reservoir: "We store enough water for the golf course, you know, for the whole year. And we take that water at very, very low times" (C1, P2). C5, on the other hand, still draws some water from a nearby creek, but is also offsetting the water needed for irrigation: "somewhere around $70-75 \%$ of the rainfall that falls on this property goes back into our ponds, and we're using that as well. We have about a 44 million gallon holding capacity on site as well ... so a lot of the snowmelt and things of that nature, the rainfall that we do catch, we do reuse it. It is a significant amount of water" (C5, P1). Three additional courses have plans to upgrade their antiquated irrigation systems (C2, P1; C3, P1; C4, P1; and C4, P2). It should be noted that these irrigation upgrades were prime examples of "policy as activity" moving towards "action."

Water conservation was also achieved at C5 through the use of soil moisture meters. C5, P1 explained that rather than relying on evapotranspiration rates of the day, which do not take into account the several microclimates around the property, these meters allow superintendents to probe each green to determine the percentage of moisture within the soil. It was further explained that at $10 \%$ moisture the plant wilts and is healthiest at $18 \%$ moisture. Therefore, soil moisture meters allowed readings before and after watering to achieve optimal levels, without overwatering and therefore wasting precious resources. Although C5, P1 indicated that soil moisture meters have helped with water conservation throughout the industry, this technology was not discussed at any of the other courses under review.

Protecting on-course waterways was also part of water management programs, specifically the use of buffer zones along creeks and rivers to prevent water contamination. Participants C1,P3 and C5,P1 described the process of maintaining buffer zones when applying fertilizers and pesticides around the course. Further, C4,P2 described "having no-mow areas or low-mow areas to, you know, create that buffer from runoff."

With respect to internal water management, the most common initiative included low-flow toilets and fixtures in bathrooms, locker rooms, and kitchens. The clubhouses of C1, C2, C3, and C4 are all more than 80 years old, and upgrades have been completed over the years. Each course had updated bathroom fixtures to be low flow, to some extent; however, the lack of complete conversion identified by participants C2,P1, C3,P2; and C4,P2 and observed during site tours suggested that this "policy as action" implementation instrument required further work to achieve greater ES.

The third key instrument discussed as being a key element furthering the implementation of ES policies at courses involved programs around energy conservation. The primary initiative around energy conservation was lighting conversion throughout the clubhouse and outside property to include LED bulbs and some motion sensors. These conversion projects were being undertaken at all courses; however the extent to which they have been completed varies. C1 completed their lighting conversion throughout the clubhouse, parking lots, and maintenance areas, thereby being classified as "policy as action." Conversely, the lighting conversion projects at C2, C3, C4, and C5 have been labeled "policy as activity" moving to action, as they were in the process of being completed.

Beyond lighting, energy conservation was achieved through the use of Energy Guide appliances and machinery. Further, with respect to "policy as action," Energy Guide logos were also observed on various pieces of office equipment (e.g. computers, printers, photocopiers) and kitchen appliances at all five courses during site tours. It was apparent that the choice to purchase Energy Guide was quite common across courses, perhaps due to the increased availability of Energy Guide items provoked by the overall environmental consciousness of consumers across various industries.

An interesting contradiction was noted between courses with respect to replacing windows to increase energy efficiency. As previously noted, many of the clubhouses visited were over 80 years old and therefore were not necessarily energy efficient. Therefore, despite recognizing the potential of energy conservation through window replacements, the overall deterioration of the aging buildings prevented implementation for fear of little overall impact. On the contrary, C2,P1 described a "policy as activity"' to "action" initiative in which the windows of the clubhouse are being replaced with more energy efficient ones. Further, and perhaps a demonstration of a common ground between ES and preserving tradition, C3,P2 described the window retrofitting at that club: "As we change the windows we obviously go with the most efficient that we can. Something that works for the look and feel of that room as well." While the traditional aspects of history-rich clubhouses are important to preserve, it has been 
demonstrated by C2 and C3 that ES can still be achieved without compromising the integrity of the building.

Finally, tree projects were completed at four of the five courses (C1, C2, C4, and C5) and involved removing dead/damaged/diseased trees that may be hazardous to golfers; promoting stronger, healthier tree species; and increasing airflow and sunlight, thereby promoting stronger turf. C1,P2 discussed the electronic tree inventory in which every tree on the course was GPS mapped and logged; the Club also consciously avoided planting species prone to disease to avoid pesticide, fungicide, and herbicide use. As a result of C1's proactive tree program, the course is exempt from the city's tree bylaw, allowing for more freedom during course maintenance. This comprehensive tree program is a prime example of an implementation instrument that allows the club to pursue and achieve a number of ES goals.

Similarly, C2 has a strategic tree management plan in place. Under local government bylaws, the course is required to replant "three-to-one": "One tree down, we have to plant three" (C2,P1); further, conscious decisions are made about what trees are being planted to satisfy this obligation: "It's not just planting trees; it's planting trees and shrubs in combination, trying to create, sort of a, woodlot system" (C2,P1). Much like C1, C2 avoids planting species that are prone to disease, thereby creating a more sustainable tree system. C5,P1 described a similar system in place at that course that involved working with the regional forester to take "a sustainable approach to the things that we have to do." In addition to the benefits of stronger, healthier trees on the course, tree removal was noted at both C2 and C4 for the additional benefits provided by increasing sunlight and airflow for turf. C4 underwent "heavy tree removal in about six areas out on the golf course" $(\mathrm{C} 4, \mathrm{P} 1)$ to rectify problems with turf on those greens. Observations revealed greens in low-lying areas of the course, surrounded by embankments that had previously been crowded by mature trees. As a result of the tree removal, these greens now receive adequate sunlight and airflow to maintain healthy turf, without altering the integrity of the golf course design.

Training/education was identified as a unique instrument categorized solely as "policy as activity." Training around recycling programs is required, according to C2,P1 and C3,P1, to ensure that garbage is being separated effectively. Further, C2,P1 suggested that training employees to turn off lights and turn down thermostats when leaving rooms around the club could aid in energy conservation. Finally, educating membership about ES initiatives, particularly around turf, ensured they understood the decisions that are being made and to what extent they affect the playability of the course (C2,P1).

\subsection{Dimensions of Convergence: Momentum}

Momentum referred to "the weight of support, especially political support, behind a policy aspiration" (Houlihan, 2012, p. 113). Each of the aforementioned implementation instruments required momentum for support and to progress toward having a positive environmental impact. While Houlihan (2012) specifically noted "support" for policy aspiration, it was found that the same sources of momentum had the potential for a negative effect, showing a lack of support for ES initiatives and therefore acting as a deterrent in some cases. For example, both support and a lack thereof were noted from members, political entities, employees, external agencies, and the golf industry; likewise, monetary resources provided support, but a lack of these same resources acted as a deterrent for ES initiatives. In addition to these sources of momentum, support has been provided to individual courses through employee training, legal entities, the ownership organization, and shareholders. Alternatively, a lack of communication and resources (e.g., time, technology, and up-to-date infrastructure) has acted as momentum deterrents at individual courses. Although momentum appears to exist in multiple forms and in varying capacities, member support or lack thereof was the most dominant aspect of momentum, with support noted at all five courses and a lack of support noted at four courses. It was noted that political and external entities both provided support at four courses and acted as a deterrent at two courses and a single course respectively. Finally, monetary support was noted as providing momentum at two courses but was noted at all five courses as being a deterrent to ES because of a lack of monetary resources.

This is not to say, however, that a lack of interest from members is universal. C3,P1 recognized that they cannot rely on member support for ES initiatives, or pro environmental projects would rarely be passed As an example, there was push-back from members at C3 when styrofoam cups were replaced with a more environmentally friendly alternative, but the decision was made to pursue this and other ES initiatives, despite the backlash.

The generally care free attitude of golfers toward ES initiatives was found to be interesting, most notably because of the stark contrast between the opinions of extreme sport participants, as discussed by Brymer et al. (2009), and golfers with respect to the natural environment. Brymer et al. found that extreme sport participants often become environmental stewards and develop a vested interested in the natural environment as a result of their sport participation. However, it does not seem as though golfers have the same reaction to sport participation, despite a 
similar connection to the environment by the very nature of the sport. Both extreme sports and golf rely on strategic use of the natural environment for a desirable playing surface, yet the participants of these sports evidently have very different opinions regarding their relationship with the environment.

Government legislation at the municipal, provincial, and/or national level, is guiding many elements of golf course operations. Specifically, IPM guidelines and tree cutting bylaws direct the use of pesticides and maintenance of trees on course property. C2 discussed the effect the municipal tree bylaw has on his work: "When we want to remove trees, and it's part of the City of [removed for anonymity] bylaw, we have to get a permit" (C2,P1). In contrast, C1 was exempt from the municipal tree bylaw because of the exceptional work they have done with trees in the past (C1,P1). C3,P1 discussed frequent contact with the local conservation authority, municipal government, and the provincial Ministry of Natural Resources (MNR): "I probably have 30 interactions with the Ministry of Natural Resources, a year ... I'm on a first-name basis with 20 people from [the local conservation authority]." The importance of these interactions was recognized by C5,P1 who stated: "We work really closely with whatever region or whatever government body we may be subject to scrutiny from." Yet, C1,P2 expressed that: "the biggest deterrent to environmental sustainability is government intervention ... It's just ... that's $a$ lot of red tape to go back and forth. And you're dealing with bureaucracies here, we're talking in terms of years, not in months or weeks" (C1,P2). It thus appeared as though government legislation provided guidelines for environmental initiatives, and while they have assisted some courses in achieving their ES initiatives, they have made the process more difficult for others. Perhaps one explanation is that rules and bylaws were made to apply universally across an entire province or country, but they do not necessarily "make sense" universally, as articulated by C1,P1. This participant indicated an issue arose when protecting a species of tree that is scare in one part of the country but plentiful in another.

An external source of support was the local conservation authorities, described by C4,P1. This participant described reaching out to this external entity prior to starting any on-course projects and working collaboratively to execute the initiative in the most environmentally conscious manner. Subsequently, however, C4,P1 acknowledged that this supportive relationship does not exist at all courses and that it often depends on the region in which the course operates, as evidenced by the tenuous relationship described by C3,P1 with that course's local conservation authority. Similar to the "red tape" encountered by C1 with political entities, C3 faced a comparable challenge when trying to meet the requirements set out by the local conservation authority indicating that

the recommendations they come back with ... [pause] ... are so ridiculous from a replanting, revegetation, plant selection ... all of these things, again, are not sustainable. We can go plant $\$ 10,000$ worth of their ground-covers that we want and you turn around three months later and they're all dead. So ... we've made such an effort, for nothing! And it's all because in their playbook, that's what we need to do (C3,P1).

Once again, guidelines provided by these external entities appear to benefit some courses while hindering the ES initiatives of others.

Finally, and perhaps most logically, monetary resources provide necessary momentum to move ES initiatives forward. C3,P2 described the monetary incentive associated with ensuring efficiency in the water system in an old building, a point that can be extended to efficiencies in other areas, including energy consumption and waste management. At the same time, when asked to identify challenges to implementing ES initiatives, participants at all five courses recognized money or lack thereof as a barrier, a sample of which is provided here:

One of the things that, I guess, is the largest struggle is just the cost of doing everything" (C4,P2);"Challenges ... well, capital budget. The challenge of competing for capital dollars. Sometimes knowing that the return on investment is small (C2,P1).

Intuitively, then, if monetary resources provide momentum for ES initiatives, a lack of these same resources can slow momentum and even halt implementation. Not only is there a lack of money available to pursue ES initiatives, but also "the cost of doing business is going up higher and quicker ... So, it's very difficult ... It's tough ... It's tough to keep up" (C4,P2). The resources available to satisfy golfers' demands is growing scarce, negatively impacting the momentum behind "additional” projects, such as ES initiatives.

It is evident that many of the same entities have acted as both inputs and sources of momentum for ES initiatives. Member, political, external, and monetary support not only provides resources to pursue ES initiatives, but also guide and support the projects to achieve the desired impact. As such, it is crucial for operators to nurture these relationships to ensure continuous support throughout the policy formulation and implementation process. While momentum typically refers to support for implementation instruments, as outlined above, these same sources of momentum are shown to have an adverse effect on initiatives if a lack of support is evident. Therefore, it is 
imperative for golf course operators to advance the sources of momentum that are providing support for ES initiatives.

\subsection{Dimensions of Convergence: Impact}

Impact refers to "the effect of policy on the identified target issue/problem within a specific jurisdiction" (Houlihan, 2012, p. 113). Impact is a "crucial dimension in any analysis of convergence" (Houlihan, 2012, p. 113), as it reflects the extent to which change has been achieved as a result of policy development and implementation. In this research, the most significant and wide-reaching impacts were the result of tree work and other ES initiatives, namely water reduction, energy conservation, planning labour, and waste reduction/recycling to provide notable savings for course operators. Although none of the courses under examination have conducted analyses to provide specific savings figures, participants at each of the five clubs noted a positive monetary impact as a result of ES initiatives.

Tree work, though it may seem somewhat contradictory, was one of the major ES initiatives. Additionally, regenerative planting was one of the ES initiatives that had a positive impact on the environment; course operators were choosing to plant stronger, more resilient species of trees that were not susceptible to pests to ensure "survivability" in forest areas of the courses (C1,P2; C2,P1; C3,P1; C4,P2; and C5,P1). Further, it was stated that "we've learned that the younger tree will actually clean the air much more effectively ... than an older tree that may be three or four times the size" $(\mathrm{C} 5, \mathrm{P} 1)$; as such, tree projects are not only promoting stronger species that require fewer resources for maintenance but are also improving air quality through natural photosynthesis. Further, providing the grass with sunlight to survive and produce its own food through photosynthesis and ample oxygen to cool itself by taking water from the soil were primary goals when determining which trees to remove during the greens improvement project (C4,P2). Additionally, decreased pesticide use also reduced the amount of labour needed to spray trees and greens. On the whole, tree projects have the potential to have both a positive environmental impact and to generate savings for the course through reduced resource requirements.

Monetary saving was consistently mentioned by participants as a result of ES initiatives. Water use reduction was noted to provide savings through enhanced irrigation systems at C2 and C3, projects that also provided a ROI over time. Likewise, the water reservoir project at $\mathrm{C} 1$ and retrofitting bathroom and kitchen fixtures at each course provided a ROI and savings into the future with reduced water usage. LED conversion projects at C1, C2, C3, and C5 provided a monetary impact through energy conservation. The ROI for LED conversions was noted by course superintendents at C1 and C2: "I felt like there was a lot of opportunity to save on energy, and we've seen that already. So we have seen savings". C2,P1 elaborated that in addition to reduced energy consumption, the increased lifespan of LED bulbs reduces the labour required to purchase and install replacement bulbs.

Waste reduction/recycling had a positive financial impact for course operators. C1 used the milled wood from trees removed during the water reservoir project to build fences, signs, and a lunch room table, while using woodchips from the remaining trees in mulch beds and around the bases of trees throughout the course (C1,P3). Similarly, $\mathrm{C} 4, \mathrm{P} 2$ explained that after the tree removal for the greens improvement project "all the lumber was reused. We took almost 65,000 board feet off site to the lumber mill ... All of the remaining product was cut into firewood and sold by another company." C5 used wood chips from trees that had been removed to firm up areas of the course that were trampled. Further, food was utilized to its fullest extent, as noted at C3 "being able to break down product and use it to its fullest is better, not only for the environment, but also for its cost benefits" (C3,P2); and by C5,P1 who explained the chef purchases ingredients that can be used in multiple dishes on the menu to reduce waste.

Paradoxically, the positive financial impact was enjoyed only by those courses that managed to secure the resources necessary for input and momentum of ES initiative implementation.

\subsection{Impression Management}

Impression management was defined as "the conscious or unconscious attempt to control the images that are real or imagined in social interactions" (Schlenker, 1980, p. 6 as cited in Fisk \& Grove, 1996, p. 7). Impression management can occur through both interpersonal exchanges (e.g., face-to-face interaction between the buyer and seller) and general marketing (e.g., corporate image advertising, organizational publications, and so on; Fisk \& Grove, 1996). Within this manuscript, impression management was considered in terms of how information was disclosed to the researcher and how information is being shared with stakeholders of the clubs.

On the whole, participants seemed to recognize successes and areas of potential improvement in ES initiatives equally. Interviewees were asked about the priority the club places on ES initiatives and the subsequent commitment the club has shown to executing those initiatives using a 5-point Likert scale (i.e., 1 = very low, 5 = very high). Interestingly, although individual participants provided different values for priority and commitment, the overall 
results were identical for both considerations: mean $=4$, median $=4$, mode $=4$, and range $=2$ (between 3 and 5 ).

Overall, participants valued commitment to ES equal to or slightly lower than priority to ES initiatives, indicating the clubs are working toward goals for greener operations. The consistent result of 4 (i.e. high) across mean, median, and mode for both priority and commitment to ES suggests that participants recognize their above average incorporation of ES initiatives, as evidenced by ACSP certification, but recognize that there was potential for improvement and greater incorporation of ES initiatives into operations. Consistently throughout interviews, participants candidly admitted when the club was not incorporating a specific ES initiative or when they were working toward such incorporation: "I think it's [ES communication on their website] one of those things that you could probably always do more" (C4,P2). In some instances, participants went a step further to acknowledge how a particular ES initiative the researcher asked about would benefit the club: "We don't have an environmental committee and any leadership ... Which is actually a really good idea, actually" (C3,P1). Consistent with Bansal and Kistruck (2006) who stated, "acknowledgements are more effective than denials" (p. 177), participants acknowledged areas of their operations that may be lacking in ES and seemed willing to consider improvements and incorporation moving forward.

Information was being communicated to stakeholders using impression management to combat stereotypes about harmful practices at golf courses (C4,P2) and stakeholder beliefs about how golf courses are handling ES initiatives $(\mathrm{C} 1, \mathrm{P} 2)$. As such, C4,P2 explained the need "to promote the fact that golf courses aren't necessarily dumping grounds ... as some people may think ... in urbanized areas they are the last refuge for environment for critters and deer and all those things."

Overall, the Dimensions of convergence at the golf courses under study were pursuing environmentally conscious maintenance practices; however, they did not communicate these practices well. These practices must, then, be communicated more adequately to those individuals and groups outside the course operations. C1 provided an anecdote that outlined how the general public perceived "perfect" conditions on golf courses:

I saw a newspaper article the other day and somebody said, sort of flippantly, that golf courses continue to use water when these restrictions are on. Well we don't. We stored it. We spent a lot of money and we store the water ...we don't have to take that water off the system when it's under strain (C1,P2).

A balance is needed between a demand for pristine conditions (C5,P1) on golf courses and the public disapproval of maintenance practices that may harm the natural environment. In this regard, then, impression management practices at courses engaged in ES need to promote the positive environmental impact of course maintenance operations while clarifying the requirements associated with the most desirable course conditions.

Interviewees elucidated how impression management is being employed at courses. C2,P1 indicated the importance of utilizing the community involvement section of the ACSP manual to educate the public; in contrast, C2,P1 stated that "you know, if we're not in the newspaper, it's probably a good thing." The contrast demonstrated between embracing education through community involvement and avoiding being reported in the newspaper suggested that course operators see the value of impression management and desire to be in control of messages being distributed about practices.

Further, there appears to be a correlation between impression management techniques and education about ES initiatives. Educating employees about ES initiatives also generates an impression surrounding the level of commitment employees perceived and the subsequent actions of these employees. According to C1,P3, reports about ES initiatives were being consistently included in employee newsletters at that club, but had not done so in many years, unless about a specific imitative or major project, such as the water reservoir $(\mathrm{C} 1, \mathrm{P} 2)$. The same sporadic reporting practices were also noted by C4,P1. In contrast, C3,P1 explained that he makes a conscious effort to pick something to do with the environment, whether it be related to a project on the course or something that is naturally occurring with wildlife, to feature in each e-newsletter to members. In terms of impression management with members, C1,P1 expressed, "we ... learned that communication is the key and that ... we own the process ... They're [members] the ones that oversee what we do. But we can control a little bit of the process". Being in complete control of how information is disseminated to members allows operators to manage their impressions more easily than with other stakeholders, particularly the general public.

One area that seems to be severely lacking at all courses is external communication to the general public. C3,P2 did explicitly indicate that "being a private club, we don't communicate a lot outside"; however, this point was more thoroughly demonstrated during the content analysis of each course's website. Of the five courses under consideration, three courses (C2, C3, \& C5) gave no indication that they were ACSP certified. As such, the lack of information about ACSP membership and ES initiatives on course websites is a missed opportunity. 
The other two courses (C1 \& C4) under consideration had dedicated "Audubon" tabs on their websites; here, both clubs included documentation to validate their ACSP certification. C1,D1 provided general information about the ACSP for Golf, including a statement from an Audubon staff ecologist about the club's membership. Alternatively, the website of C4, D1 provided ample detail about specific ES initiatives being undertaken at the course, including the club's creek project and various wildlife protection ventures. However, in both cases, the researchers questioned how often the information on these sites is updated, based on a "broken" link to the Audubon website on C1's page and the most recent post on C4's page being dated early 2011. Given the conception by the general public that golf courses are notoriously harmful to the environment (Calderwood, 2008), there is a considerable lack of impression management tactics being used by these courses.

One of the primary issues is ensuring that the message reaches the desired target. Regardless of how thoroughly messages are constructed to generate a desired impression, if the target audience does not receive the message, there is little more course operators can do. C1,P1 expressed that their "internal stakeholders are all members and they're all shareholders. They're all part owners. So there's a high degree of responsibility there ... And we communicate ... to the extent that they are willing to pay attention." Further, C5,P1 suggested that oftentimes ES initiatives "are things that are tough to get the general public to understand." The lack of concern for ES initiatives coupled with an inability to understand created a challenge for course operators trying to manage impressions of their clubs. Advancing message framing is one technique that can be used to overcome this challenge.

\subsection{Message Framing}

Message framing is defined as the extent to which "favorable or unfavorable associations with positively or negatively phrased attribute labels mediate the evaluation of consumer goods" (Levin, 1987 as cited in Levin \& Gaeth, 1988, p. 374). Message framing "presupposes that the way an audience responds to a particular message can depend on how the message is composed" (Cheng et al., 2011, p. 49). Based on Levin et al.'s (2002) message frame typologies, interview transcripts and documents obtained from each course were analyzed, which determined goal message framing was used most frequently. Additionally, it was noted that messages were framed positively more often than negatively, and that written communication was less effective than verbal when conveying messages to stakeholders.

According to Levin et al. (2002), goal message framing is persuasive in that it either emphasizes the positive consequence of performing an act or the negative consequence of not performing that same act. Under particular consideration is the message framing used to discuss ES plans with members, as these individuals play an important role in ensuring adequate financing for these projects. In general, goal message framing involves explaining, "okay, this is what we're doing and why" (C5,P1). In greater detail, these messages are shown to either focus on the positive benefit of pursuing ES initiatives, such as: "We're working on a long-range plan where we're trying to do is to educate the membership on the benefit of regrowing our greens and surfacing them with the creeping bent grass, which requires less fertilizer, water, pesticides" (C2,P1); or, the focus is on the negative impact of not pursuing ES initiatives, such as: "to get the whole membership on board ... as many as you can let them understand the problems that we have" $(\mathrm{C} 4, \mathrm{P} 1)$. Perhaps one of the most telling examples was provided by participants at C1 who explained the process by which the multi-million water dollar reservoir project came to be approved.

It took a really good effort on behalf of [the course superintendent] and a number of volunteers to carefully explain to the members, it was their money ... over the years, why they had to do this and why we had to be ahead of the curve. And what was going to happen with water management going forward and restrictions and how we were better to bite the bullet and do it now (C1,P1).

A prime example of goal message framing came from C1,P2 who claimed, "they [members] made that decision right away because we explained it." The pervasiveness of goal message framing was intriguing, given that Levin et al. (2002) found this typology to be the least successful of the three. Perhaps, then, there is greater potential for positive results from message framing using other typologies.

Communication with internal and external stakeholders when attempting to gain approvals for ES initiatives was explicitly discussed in terms of positive versus negative frames at C1 and C2. C2,P1 that communication is "always positive ... Honestly, it's explaining why we've taken on this initiative and the impact it has on operating costs and the environment." Moreover, he explained that "I don't like to put the board or other amateurs with their backs to the wall, in any instance. So to me, that's when you're in crisis mode." It was evident that positively framed messages were preferred as they gave a favourable impression to members, thereby increasing the potential for project approval. The idea of "scare tactics" was also discussed at C1, where the COO explained that negatively framed messages would not be as effective with their membership as those with a positive connotation: 
Our clientele are not easily manipulated or duped ... they're very highly educated...and they're very analytical, and they're very involved in the club. They're our owners... we can't pull something over on them by using scare tactics. But it ... once we convince them based on logic and, and looking towards the future, generally we've got them on board (C1,P1).

Beyond communication with members, messages to the other stakeholders and the general public around day-to-day ES initiatives are also framed in a positive manner. Communication on the website of C1, D1 used words like "proud" and "sanctuary" to describe the course and its ACSP membership. Meanwhile, the Twitter feed by C4, D7 revealed thorough explanation of ES initiatives as they were being executed (e.g., "16C soil temp triggers $103 \mathrm{ml}$ rate of Banner Maxx. Forsythia bloom triggers preventative application of crabgrass. More crabgrass tomorrow" and updates on the results of ES initiatives post-implementation e.g., "14 green soaking up some sun! It has never received this much sun since it was built in 1997!"; post included a picture of the green). As evidenced in these examples, the messages, though short, were consistently framed in a positive manner to promote ES initiatives to club members, industry colleagues, and anyone from the general public who may visit the Twitter feed.

With respect to medium of communication, C1,P1 explained that one of the club's members was able to explain the water reservoir project in great detail, which proved beneficial in getting other members to understand the project; in contrast, C1,P2 explained that members will not read emails from the Club, particularly if they contain "technical data" which severely limits the communication with the important stakeholders. It was stated that "when you write that down and send it in a broadcast email, and some people read it and some people don't, or they read it and they don't understand it and they take it out of context" (C1,P2). Both C2,P1 and C3,P2 stressed the importance of verbal communication within the organization, especially among management, to, in turn, communicate ES messages to employees. However, it was noted that communication with members and other stakeholders is often through email blasts. Courses seem to rely mostly on written communication (e.g., e-newsletters, blogs, annual reports, etc.), but recognize that this medium is not necessarily the most effective, because these individuals must be willing to actually read the messages being distributed. Of note with respect to written communication, though, is the prevalence of electronic messages rather than printed newsletters; although email is a more timely mode of communication, it also conveys a message of environmental consciousness to stakeholders by avoiding the use of paper.

It was found that goal message framing was the primary typology utilized by course operators, despite being dubbed the least successful of the three, as outlined by Levin et al. (2002). However, in accordance with Levin et al.'s suggestions, course operators most often framed messages around ES in a positive, rather than negative way. Finally, it was determined that message medium is as important, if not more important, than the message itself. Written messages often failed to reach stakeholders, while verbal/face-to-face communication afforded the opportunity for course operators to fully explain ES initiatives and develop an interest in these projects.

\section{Conclusions and Implications}

The purpose of this research was to explore ES initiatives at top-ranked Ontario golf courses using interviews, observations, and unobtrusive data (document) collection for content analysis. Five ACSP certified golf courses located in southern Ontario that were ranked within the top 50 of the Score Golf Top 100 golf course rankings from 2012 (Score Golf, 2012) were examined using the dimensions of convergence, impression management, and message framing constructs to frame the research. Environmental aspects of the research were guided by adaptations of CSA and SSET considerations. It was concluded that each course under examination approached ES in a slightly different manner. Motives and inputs shared similarities, but the combination of these aspects and the extent to which each guided ES initiatives varied significantly from course to course. However, the specific programs and actions pursued at each course demonstrated that there were multiple perspectives from which course operators approached engagement in ES initiatives.

The most prevalent momentum factors were noted as having the ability to both promote and inhibit the implementation of ES initiatives; member, political, external, and monetary support and/or deterrence were declared as momentum factors. Meanwhile, initiatives that received adequate resources and momentum saw financial savings as the most considerable impact. Overall, perhaps the most ubiquitous aspect of incorporating ES initiatives into operations was securing funding for initial execution (i.e., inputs) and completion (i.e., momentum). ROI and monetary savings were major impacts of ES initiatives; however, for these savings to be realized, initiatives must be viewed as an investment rather than expenses.

With relation to communication of ES initiatives, positive impression management and message framing were utilized 
by course operators. Still, there appears to be a disconnect between the desired impression and the message frame, as goal message framing and nonverbal communication were being exercised most frequently, despite providing varied results. Overall, the following underlying research questions were answered as follows:

\subsection{How Are Golf Courses Adapting to Safeguard the Natural Environment?}

Golf courses are reliant on the natural environments in which they operate; the researcher found that course superintendents were exceedingly aware of this fact and sought to preserve nature to the greatest extent possible. Major efforts to safeguard the natural environment have come from tree removal and water conservation projects. Tree projects have shown significant benefits for courses pursuing ES initiatives, as replanting of healthier, stronger species has not only improved air quality but will reduce the need for excessive maintenance and chemical treatment in the future. Proactive tree planting is easy to implement throughout the industry, yet is show to have a significant, positive impact on the environment. Courses engaged in tree removal have also committed to strategic replanting in which strong species of trees are planted at a replacement ratio of three-to-one to create a woodlot system. By adapting golf course operations to maintain the property in the most natural way possible, the sport is making strides toward safeguarding the natural environment.

By collecting and storing water, golf courses have become less dependent on creeks, rivers, and other naturally occurring bodies of water. Additionally, by upgrading to more efficient irrigation systems that allow for more specific watering around the golf course, Superintendents have been able to create ideal turf conditions with minimal water. C1's water reservoir project, which added 20 million litres to the holding capacity of the club's irrigation system, also had a significant impact on maintenance operations. By collecting and storing rainfall and ice-melt throughout the year, the course was able to operate its irrigation system completely "off-the-grid" rather than drawing from alternative water sources, such as local creeks and waterways. C5 demonstrated an advanced technique in course irrigation through its use of soil moisture meters, which give specific readings before and after watering greens and fairways, thereby eliminating excessive and unnecessary watering.

In addition to the water conservation and tree removal projects noted above, course operators have made conscious decisions to adapt maintenance practices to be more environmentally sustainable. Most notably, many superintendents have introduced low- and no-mow areas to their courses. The benefits of having these areas are two fold: a) reducing the amount of space on the course that requires daily maintenance, also reduces emissions from mowers, water usage for irrigation, and application of fertilizer/pesticides; b) low- and no-mow areas act as channels for wildlife, thereby increasing their mobility and preserving their natural habitats. Though low- and no-mow areas have been a change to the "traditional" appearance of courses, superintendents were sure not to change the overall layout of the track. The tradition of clubhouse architecture was also noted at many of the courses in this case study. Even with the desire to preserve the tradition of these 80-plus year old clubhouses, course operators have made proactive decisions to retrofit these spaces with LED light bulbs, Energy-Star appliances, and low-flow plumbing fixtures to become more environmentally sustainable.

\subsection{Why or Why Not Are Golf Courses Moving to ES?}

Despite a number of calls for golf ES within industry literature (Calderwood, 2008) it still remains that golf course operators are moving toward ES at different rates. In this research, the question of why or why not courses are moving to ES was answered through an examination of several dimensions of convergence. Motives for engaging in ES initiatives is, perhaps, the most logical answer to this question. A number of course operators indicated that greening is part of a CSR initiative or greater ethical obligation. More specifically, courses with superintendents who have a personal commitment to the environment (C1, C2, C3, \& C4) saw a stronger commitment to ES. Additionally, inputs and momentum are closely tied to ES initiatives, as these items provide resources and support to implement specific plans and projects. Course operators consistently noted that while monetary support is needed to implement ES initiatives, securing those funds often poses a challenge, thereby inhibiting green projects. Ironically, the impact of ES initiatives often comes in the form of money. Course operators who are able to execute ES initiatives to the point of seeing the impact note that ROI is justification enough to continue with these projects; however for those courses where projects are slow moving, the ROI is never realized, or is realized too late to encourage a greater move to ES. Finally, managing impressions of stakeholders, particularly members and political entities, was noted as having a positive effect provided the benefits of ES initiatives were communicated. A lack of impression management, however, left course operators without the necessary support from stakeholders.

\subsection{What Are the Arising Barriers to ES in Golf and How Can They Be Overcome?}

While the clubs analyzed for this case study have achieved a higher level of ES in their golf course operations, 
significant barriers were still noted by key actors. A lack of support for ES initiatives from members and political entities was show to slow the approval, planning, and implementation processes. Further, there was an oft-cited contradiction between member expectations for course conditions and the perception of harmful course maintenance practices. Finally, a severe lack of monetary support for ES initiatives has prevented course operators from incorporating greening practices and realizing the eventual ROI. While these barriers were noted by key actors at private clubs, given the nature of these barriers, they are presumably issues faced by most golf course operators pursuing ES initiatives.

To overcome these barriers to golf ES, the researcher recommends the advanced practices by courses noted above and proposes the following courses of action, as realized throughout the research process. Formalized ES teams with leadership have not been established at these courses, but rather are ad hoc when an ES project is pursued. Nevertheless, it appears as though the elements of an ES team are already in place at many courses (i.e., top-level management communication around ES initiatives) and that individuals who provide internal expertise, such as the course superintendent, could act as ES leaders. As such, based on the results of this study, the researcher recommends that Clubs utilize the resources they already have in place to create a formalized ES team with management representation from each department, similar to a health and safety committee, and that one of the individuals who currently provides internal expertise act as the leader of this committee. A formalized ES team has the potential to make a statement to stakeholders about the club's commitment to ES initiatives and the priority placed on the natural environment.

Once this ES team is in place, the researcher further recommends formalizing ES initiatives in a written plan, preferably updated yearly, to guide generation and implementation. Within this plan, programs such as those described in the above results (e.g., water reservoirs, tree projects, recycling programs, energy and water conservation projects through retrofitting, etc.) should be outlined in detail, including timelines for completion and potential/desired impacts. Further, this plan can be used to provide detailed information about projects to stakeholders, thereby acting as a means to secure funding from members and alternate sources. The lack of member and monetary support was noted as a significant barrier to golf ES; both of these issues can be overcome by using an ES plan to obtain the necessary financial resources through member education.

In terms of communication, positive message framing was shown to be effective at these courses and should continue to be used accordingly. Further, ES plans should be verbalized to members and staff through informational and training sessions. Impression management was most efficiently used by those courses that engaged in constant communication with stakeholders. C3 consistently gave details surrounding ES initiatives, whether they be every day actions or large-scale projects, to members and employees, thus keeping these individuals involved in the process. While having the ES plans outlined in writing is valuable for those who have a vested interest, as evidenced above, few people seek out that information. Across courses, verbal communication was shown to be more effective and allowed for advances in successful impression management; therefore those leading ES initiatives should make it a priority to explain the planning and implementation to stakeholders with face-to-face communication. The courses using verbal communication, particularly to explain major ES initiatives, have shown greater success and should guide others to do the same.

With respect to message framing, C5 demonstrated a more advanced typology through its use of attribute message framing when proposing projects to members. The use of specific numerical figures, including the initial investment required and expected ROI, allowed course operators to positively frame messages with success rates, rather than simply the goals they wish to achieve with the initiative. The researcher concludes that research be conducted at individual golf courses to determine the success rates of ES initiatives and shared across the industry to allow for collaborative attribute message framing. As discussed by Levin et al. (2002), attribute message framing sees the evaluation of an object or event being more favorable if the message is framed positively rather than negatively; these messages could include success rates and ROIs from the aforementioned research conducted at courses. While goal message framing was found to be most commonly used at golf courses currently, the research concurs with Levin et al. that attribute message framing could see more favourable results.

\section{Limitations and Future Research}

A substantial limitation is the bounded geographical region from which the golf courses were drawn. Given that there are thousands of courses around the world, conclusions derived from this research can be extended only in a limited capacity. Moreover, the courses examined were private clubs, representing only a small percentage of all golf courses in the country. Finally, the research used the ACSP certification list to identify courses actively engaged in 
ES initiatives; however, some of the over 95\% of Canadian courses that are not ACSP certified may still be incorporating ES initiatives into their operations. Based on the limitations, future research on ES at golf courses should seek to discover the best practices at publically accessible courses and/or those without ACSP certification located outside of southern Ontario.

Future research may utilize the concept of resilience by Folke (2006) to examine how entities adapt in times of change and uncertainty. With ever-changing technology in the golf industry and continuous advancements in ES initiatives, it is reasonable to assume that golf course operators will show some level of resilience to adapt to these changes. As such, future research on ES initiatives at golf courses could focus on the concept of resilience.

\section{References}

Alam, F., Steiner, T., Chowdhury, H., Moria, H., Khan, I., Aldawi, F., \& Subic, A. (2011). A study of golf ball aerodynamic drag. Procedia Engineering, 13, 226-231. http://dx.doi.org/10.1016/j.proeng.2011.05.077

An, M., \& Sage, G. (1992). The golf boom in South Korea: Serving hegemonic interests. Sociology of Sport Journal, 9, 372-384.

Andreff, M., \& Andreff, W. (2009). Global trade in sports goods: International specialisation of major trading countries. European Sport Management Quarterly, 9, 259-294. http://dx.doi.org/10.1080/16184740903024029

Audubon International. (2004). Audubon cooperative sanctuary program for golf courses: Certification handbook. Troy, NY: Audubon International.

Audubon International. (2013a). Audubon cooperative sanctuary program for golf. Retrieved February 24, 2013 from http://www.auduboninternational.org/acspgolf

Audubon International. (2013b). Audubon cooperative sanctuary program for golf members. Retrieved February 24, 2013 from http://www.auduboninternational.org/acsp-golf-certified

Audubon International. (2013c). Frequently Asked Questions. Retrieved February 24, 2013 from http://www.auduboninternational.org/acspgolf-faq

Bansal, P., \& Clelland, I. (2004). Talking trash: Legitimacy, impression management, and unsystematic risk in the context of the natural environment. Academy of Management Journal, 47, 93-103. http://dx.doi.org/10.2307/20159562

Bansal, P., \& Gao, J. (2006). Building the future by looking to the past: Examining research published on organizations and environment. Organization \& Environment, 19, 458-478. http://dx.doi.org/10.1177/1086026606294957

Bansal, P., \& Kistruck, G. (2006). Seeing is (not) believing: Managing the impressions of the firm's commitment to the natural environment. Journal of Business Ethics, 67, 165-180. http://dx.doi.org/10.1007/s10551-006-9021-9

Barrett, J., \& Scott, A. (2001). The ecological footprint: A metric for corporate sustainability. International Journal of Corporate Environmental Strategy, 8, 316-325. http://dx.doi.org/10.1016/S1066-7938(01)00132-4

Bartlett, M., \& James, I. (2011). A model of greenhouse gas emissions from the management of turf on two golf courses. Science of the Total Environment, 409, 1357-1367. http://dx.doi.org/10.1016/j.scitotenv.2010.12.041

Briassoulis, H. (2007). Golf-centered development in coastal Mediterranean Europe: A soft sustainability test. Journal of Sustainable Tourism, 15, 441-462. http://dx.doi.org/10.2167/jost722.0

Brooksbank, R., Garland, R., \& Werder, W. (2012). Strategic marketing practices as drivers of successful business performance in British, Australian and New Zealand golf clubs. European Sport Management Quarterly, 12, 457-475. http://dx.doi.org/10.1080/16184742.2012.688755

Brouillette, M. (2010). Putter features that influence the rolling motion of a golf ball. Procedia Engineering, 2, 3223-3229. http://dx.doi.org/10.1016/j.proeng.2010.04.136

Brymer, E., Downey, G., \& Gray, T. (2009). Extreme sports as a precursor to environmental sustainability. Journal of Sport \& Tourism, 14, 193-204. http://dx.doi.org/10.1080/14775080902965223

Calderwood, J. (2008, Summer). Unfair environmental pressures, or a new improved brand of golf? Golf Business Canada, 6.

Canadian Standards Association. (2010). Requirements and guidance for organizers of sustainable events. Mississauga, Canada: Canadian Standards Association. 
Cantelon, H., \& Letters, M. (2000). The making of the IOC environmental policy as the third dimension of the Olympic movement. International Review for the Sociology of Sport, 35, 294-308. http://dx.doi.org/10.1177/101269000035003004

Cassell, C., \& Symon, G. (2004). Essential guide to qualitative methods in organizational research. London, UK: Sage. http://dx.doi.org/10.4135/9781446280119

Ceron-Anaya, H. (2010). An approach to the history of golf: Business, symbolic capital, and technologies of the self. Journal of Sport and Social Issues, 3, 339-358. http://dx.doi.org/10.1177/0193723510377317

Chalip, L. (2006). Toward a distinctive sport management discipline. Journal of Sport Management, 20, 1-21.

Cheng, T., Woon, D., \& Lynes, J. (2011). The use of message framing in the promotion of environmentally sustainable behaviors. Social Marketing Quarterly, 17, 48-62. http://dx.doi.org/10.1080/15245004.2011.570859

Choi, J. (2010). The impact of ethnic diversity on the Ladies Professional Golf Association: A case study of Anheuser-Busch and its sponsorship objectives and strategies. Sport Marketing Quarterly, 19, 51-57.

Commission of the European Communities. (2001). Promoting a European framework for corporate social responsibilities, COM (2001) 366 final, Brussels. Belgium.

Creswell, J. (2007). Qualitative inquiry and research design: Choosing among five approaches, (2nd ed.). Thousand Oaks, CA: Sage.

Daddario, G., Wigley, B. (2006). Prejudice, patriarchy, and the PGA: Defensive discourse surrounding the Shoal Creek and Augusta National controversies. Journal of Sport Management, 20, 466-482.

Dahl, R. (2010). Green washing: Do you know what you're buying? Environmental Health Perspectives, 118, A246-A252. http://dx.doi.org/10.1289/ehp.118-a246

Dewar, A., \& Kavussanu, M. (2011). Achievement goals and emotions in golf: The mediating and moderating role of perceived performance. Psychology of Sport \& Exercise, 12, 525-532. http://dx.doi.org/10.1016/j.psychsport.2011.05.005

Duffy, A., \& Dolf, M. (2010). Sustainable sport and event toolkit (SSET). Vancouver 2010 and the International Academy of Sports Science and Technology (AISTS): Lausanne, Switzerland. Retrieved from www.sustainable-sport.org

Etzion, D. (2007). Research on organizations and the natural environment, 1992-Present: A review. Journal of Management, 33, 637-664. http://dx.doi.org/10.1177/0149206307302553

Fedorcik, G., Queen, R., Abbey, A., Moorman, C., \& Ruch, D. (2012). Original research: Differences in wrist mechanics during the golf swing based on golf handicap. Journal of Science and Medicine in Sport, 15, 250-254. http://dx.doi.org/10.1016/j.jsams.2011.10.006

Fisk, R., \& Grove, S. (1996). Applications of impression management in the drama metaphor in marketing: An introduction. European Journal of Marketing, 30(9), 6-12. http://dx.doi.org/10.1108/03090569610130061

Folke, C. (2006). Resilience: The emergence of a perspective for social-ecological systems analysis. Global Environmental Change, 16, 253-267. http://dx.doi.org/10.1016/j.gloenvcha.2006.04.002

Furlow, N. (2010). Greenwashing in the new millennium. Journal of Applied Business and Economics, 10, 22-25.

Garland, R., Brooksbank, R., \& Werber, W. (2011). Strategic Marketing’s Contribution to Australasian Golf Club Performance. Sport, Business and Management, 1(2), 138-154. http://dx.doi.org/10.1108/20426781111146745

Gibson, H., \& Pennington-Gray, L. (2005). Insights from role theory: Understanding golf tourism. European Sport Management Quarterly, 5, 443-468. http://dx.doi.org/10.1080/16184740500430330

Golf Canada. (n.d.). History of Golf. Retrieved March 25, 2013 from http://rcga.org/innerpage.aspx?x=6u0mMawITYS62eG2ZX3wHzXU3NNZfipQlHsBWlOwcg\%2FM\%2BukT XecJEt11zqppmVXC

Haigh, M. (2005). Greening the university curriculum: Appraising an international movement. Journal of Geography in Higher Education, 29, 31-48. http://dx.doi.org/10.1080/03098260500030355

Haywood-Farmer, J., Sharman, T., \& Weinbrecht, M. (1988). Using simple simulation models to manage sports services. Journal of Sport Management, 2, 118-128.

Hennessey, S., MacDonald, R., \& MacEachern, M. (2008). A framework for understanding golf visitors to a 
destination. Journal of Sport \& Tourism, 13, 5-35. http://dx.doi.org/10.1080/14775080801972023

Hesse-Biber, S., \& Leavy, P. (2011). The practice of qualitative research, $\left(2^{\text {nd }}\right.$ ed.). Thousand Oaks, CA: Sage.

Hill, B., \& Green, C. (2012). Repeat participation as a function of program attractiveness, socializing opportunities, loyalty and the sportscape across three sport facility contexts. Sport Management Review, 15, 485-499. http://dx.doi.org/10.1016/j.smr.2012.03.006

Houlihan, B. (2012). Sport policy convergence: A framework for analysis. European Sport Management Quarterly, 12, 111-135. http://dx.doi.org/10.1080/16184742.2012.669390

Huertas, M., Gomis, F., Lluch, D., \& Torres, A. (2010). Analysis of the opinion about economic and social impacts of golf courses in a tourist destination. World Journal of Entrepreneurship, Management and Sustainable Development, 6, 103-117. http://dx.doi.org/10.1108/20425961201000009

Humphreys, C. (2011). Who cares where I play? Linking reputation with the golfing capital and the implications for golf destinations. Journal of Sport \& Tourism, 16, 105-128. http://dx.doi.org/10.1080/14775085.2011.568086

Hums, M. (2010). The conscience and commerce of Sport Management: One teacher's perspective. Journal of Sport Management, 24, 1-9.

Husin, S., Chelladurai, P., \& Musa, G. (2012). HRM practices, organizational citizenship behaviors, and perceived service quality in golf courses. Journal of Sport Management, 26, 143-158.

Inoue, Y., \& Kent, A. (2012). Sport teams as promoters of pro-environmental behavior: An empirical study. Journal of Sport Management, 26, 417-432.

Integrated Pest Management Accreditation Program (IPMAP). (2013). Welcome to the Ontario IPM accreditation program. Retrieved December 18, 2013 from http://www.ontarioipm.com/

International Olympic Committee (IOC). (2009). Golf and rugby to join 2016 Olympic Programme. Retrieved March 25, 2013 from http://www.olympic.org/content/news/media-resources/manual-news/1999-2009/20091/10/09/press-release-golf -and-rugby-to-join-2016-olympic-programme/

Jackson, D., Kelly, S., \& Brown, R. (2011). Design guidelines for integrating amphibian habitat into golf course landscapes. Landscape and Urban Planning, 103, 156-165. http://dx.doi.org/10.1016/j.landurbplan.2011.07.007

Jamieson, K. (1998). Reading Nancy Lopez: Decoding representations of race, class, and sexuality. Sociology of Sport Journal, 15, 343-358.

Kerr, C. (1983). The future of industrial societies: Convergence or continuing diversity? Cambridge, MA: Harvard University Press. http://dx.doi.org/10.4159/harvard.9780674497627

Krippendorff, K. (1980). Content analysis: An introduction to its methodology. Beverly Hills, CA: Sage.

Krippendorff, K. (2004). Content analysis: An introduction to its methodology (2nd ed.).Thousand Oaks, CA: Sage.

Kvale, S. (2007). Doing Interviews. London: Sage Publications.

Lambrecht, K., Kaefer, F., \& Ramenofsky, S. (2009). Sportscape factors influencing spectator attendance and satisfaction at a Professional Golf Association tournament. Sport Marketing Quarterly, 18, 165-172.

Lee, J., Kim, H., Ko, Y., \& Sagas, M. (2011). The influence of service quality on satisfaction and intention: A gender segmentation strategy. Sport Management Review, 14, 54-63. http://dx.doi.org/10.1016/j.smr.2010.02.002

Lenskyj, H. (1998). Sport and corporate environmentalism: The case of the Sydney 2000 Olympics. International Review for the Sociology of Sport, 33, 341-354. http://dx.doi.org/10.1177/101269098033004002

Lesjø, J. (2000). Lillehammer 1994: Planning, figurations and the green Winter Games. International Review for the Sociology of Sport, 35, 282-293. http://dx.doi.org/10.1177/101269000035003003

Levin, I. (1987). Associative effects of information framing. Bulletin of the Psychonomics Society, 25, 85-86. http://dx.doi.org/10.3758/BF03330291

Levin, I., \& Gaeth, G. (1988). How consumers are affected by the framing of attribute information before and after consuming the product. Journal of Consumer Research, 15, 374-378. http://dx.doi.org/10.1086/209174

Levin, I., Gaeth, G., \& Schreiber, J. (2002). A new look at framing effects: Distribution of effect sizes, individual differences, and independence of types of effects. Organizational Behavior and Human Decision Processes, 88, 411-429. http://dx.doi.org/10.1006/obhd.2001.2983 
Liamputtong, P. (2009). Qualitative research methods (3rd ed.). New York: Oxford.

Lim, C., \& Patterson, I. (2008). Sport tourism on the islands: The impact of an international mega golf event. Journal of Sport \& Tourism, 13, 115-133. http://dx.doi.org/10.1080/14775080802170346

Lockett, A., Moon, J., \& Visser,W. (2006). Corporate social responsibility in management research: Focus, nature, salience and sources of influence. Journal of Management Studies, 43, 115-136. http://dx.doi.org/10.1111/j.1467-6486.2006.00585.x

Loland, S. (2006). Olympic sport and the ideal of sustainable development. Journal of the Philosophy of Sport, 33, 14-156. http://dx.doi.org/10.1080/00948705.2006.9714698

Maas, K., \& Hasbrook, C. (2001). Media promotion of the paradigm citizen/golfer: An analysis of Golf Magazines'representations of disability, gender, and age. Sociology of Sport Journal, 18, 21-36.

Mallen, C., \& Chard, C. (2011). A framework for debating the future of environmental sustainability in the sport academy. Sport Management Review, 14, 424-433. http://dx.doi.org/10.1016/j.smr.2010.12.002

Mallen, C., \& Chard, C. (2012). "What could be" in Canadian sport facility environmental sustainability. Sport Management Review, 15, 230-243. http://dx.doi.org/10.1016/j.smr.2011.10.001

Mallen, C., Adams, L., Stevens, J., \& Thompson, L. (2010). Environmental sustainability in sport facility management: A Delphi study. European Sport Management Quarterly, 10, 367-389. http://dx.doi.org/10.1080/16184741003774521

Mallen, C., Stevens, J., \& Adams, L. (2011). A content analysis of environmental sustainability research in sport management literature. Journal of Sport Management, 25, 240-256.

Markwick, M. (2000). Golf tourism development, stakeholders, differing discourses and alternative agendas: the case of Malta. Tourism Management, 21, 515-524. http://dx.doi.org/10.1016/S0261-5177(99)00107-7

McGinnis, L., \& Gentry, J. (2006). Getting past the red tees: Constraints women face in golf and strategies to help them stay. Journal of Sport Management, 20, 218 -247.

Merriam, S. B. (2009). Qualitative research: A guide to design and implementation. San Francisco, CA: Jossey-Bass.

Mitchell, L., \& Ramey, W. (2011). Look how green I am! An individual-level explanation for greenwashing. Journal of Applied Business and Economics, 12, 40-45.

Neumann, D., \& Thomas, P. (2011). Cardiac and respiratory activity and golf putting performance under attentional focus instructions. Psychology of Sport \& Exercise, 12, 451-459. http://dx.doi.org/10.1016/j.psychsport.2011.02.002

Nicholls, S., \& Crompton, J. (2007). The impact of golf courses on residential property values. Journal of Sport Management, 21, 555-570.

Nielsen, C., \& Thangadurai, M. (2007). Janus and the Delphi oracle: Entering the new world of international business research. Journal of International Management, 13, 147-163. http://dx.doi.org/10.1016/j.intman.2006.07.003

Nurse, P. (2009). Go green off the green: Improve the environment and your bottom line. Golf Business Canada, Winter, 50-51.

Osis, S., \& Stefanyshyn, D. (2012). Golf players exhibit changes to grip speed parameters during club release in response to changes in club stiffness. Human Movement Science, 31, 91-100. http://dx.doi.org/10.1016/j.humov.2011.02.006

Paquette, J., Stevens, J., \& Mallen, C. (2011). The IOC: An interpretation of environmental sustainability, 1994-2008. Sport in Society, 14, 355-369. http://dx.doi.org/10.1080/17430437.2011.557272

Patton, M. Q. (2002). Qualitative Research \& Evaluation Methods. Thousand Oaks, CA: Sage.

Powell, K. C., \& Kalina, C. J. (2009). Cognitive and social constructivism: Developing tools for an effective classroom. Education, 130, 241-250.

Preuss, H. (2007). The conceptualization and measurement of mega sport event legacies. Journal of Sport \& Tourism, 12, 207-227. http://dx.doi.org/10.1080/14775080701736957

Priestley, G. (2006). Planning implications of golf tourism. Tourism and Hospitality Research, 6, 170-178. 
http://dx.doi.org/10.1057/palgrave.thr.6050018

Sawyer, T. (1993). Tee’d Off Women Golfers! Journal of Legal Aspects of Sport, 3, 1-14.

Schlenker, B. (1980). Impression management: The self concept, social identity and interpersonal relations. Monterrey, CA: Brooks-Cole.

Score Golf. (2012). Top $100 \quad 2012$ Special. Retrieved March 24, 2013 from http://scoregolf.com/rankings/top100/top-100-golf-courses-in-canada-2012

Seaman, A., \& McPhee, J. (2012). Comparison of optical and inertial tracking of full golf swings. Procedia Engineering, 34, 461-466. http://dx.doi.org/10.1016/j.proeng.2012.04.079

Shmanske, S. (2009). Golf Match: The choice by PGA Tour golfers of which tournaments to enter. International Journal of Sport Finance, 4, 114-135.

Slater, C., Otto, S., \& Strangwood, M. (2010). The quasi-static and dynamic testing of damping in golf clubs shafts fabricated from carbon fibre composites. Procedia Engineering, 2, 3361-3366. http://dx.doi.org/10.1016/j.proeng.2010.04.158

Smith, A., Roberts, J., Wallace, E., \& Forrester, S. (2012). Professional golf coaches' perceptions of key technical parameters in the golf swing. Procedia Engineering, 34, 224-229. http://dx.doi.org/10.1016/j.proeng.2012.04.039

Spector, S., Chard, C., Mallen, C., \& Hyatt, C. (2012). Socially constructed environmental issues and sport: A content analysis of ski resort environmental communications. Sport Management Review, 15, 416-433. http://dx.doi.org/10.1016/j.smr.2012.04.003

Stoddart, B. (2006). Wide World of Golf: A research note on the interdependence of sport, culture and economy. Sport in Society, 9, 836-850. http://dx.doi.org/10.1080/17430430600916442

Stubbs, D., \& Slack, T. (2002). An interview with David Stubbs, executive director, committed to green foundation. International Journal of Sports Marketing \& Sponsorship, 4, 287-293.

Thibault, L. (2009). Globalization of sport: An inconvenient truth. Journal of Sport Management, 23, 1-20.

Todd, S., \& Williams, R. (1996). From white to green: A proposed environmental management system framework for ski areas. Journal of Sustainable Tourism, 4, 147 -173. http://dx.doi.org/10.1080/09669589608667265

United Nations (UN) Brundtland Report (1987). 96th Plenary meeting. United Nations General Assembly, Report to the World Commission on the Environment and Development. Retrieved October 28, 2012 from http://www.un.org/documents/ga/res/42/ares42-187.htm

United Nations Environment Programme. (2008). Impact of sport on the environment. Retrieved October 14, 2012 from http://www.unep.org/sport_env/impactSport_Env.aspx

van de Pol, P., Kavussanu, M., \& Ring, C. (2012). The effects of training and competition on achievement goals, motivational responses, and performance in golf-putting task. Journal of Sport \& Exercise Psychology, 34, 787-807.

Van de Velde, L., Verbeke, W., Popp, M., \& Van Huylenbroeck, G. (2010). The importance of message framing for providing information about sustainability and environmental aspects of energy. Energy Policy, 38, 5541-5549. http://dx.doi.org/10.1016/j.enpol.2010.04.053

Weiss, O., Norden, G., Hilscher, P., \& Vanreusel, B. (1998). Ski tourism and environmental problems. International Review for the Sociology of Sport, 33, 367-379. http://dx.doi.org/10.1177/101269098033004004

Wheeler, K., \& Nauright, J. (2006). A global perspective on the environmental impact of golf. Sport in Society, 9, 427-443. http://dx.doi.org/10.1080/17430430600673449

Winn, M., \& Kirchgeorg, M. (2005). The siesta is over: A rude awakening from sustainability myopia. In S. Sharma \& M. Starik (Eds.) Research in Corporate Sustainability, Vol. 3, Strategic Capabilities and Competitiveness, pp. 232-258, Emerald Group Publishing.

Woodside, A. (2009). Applying systems thinking to sustainable golf tourism. Journal of Travel Research, 48, 205-215. http://dx.doi.org/10.1177/0047287509332335

Yin, R. (2003). Case study research (3rd Ed.). Thousand Oaks, CA: Sage Publications. 


\section{Appendix}

\section{Interview Guide}

1. How would you rate the priority the organization places on safeguarding the natural environment? 5-point Likert Scale (1 = very low; 5 = very high)

2. How would you rate the organization's commitment to engaging in initiatives to safeguard the natural environment?

5-point Likert Scale (1 = very low; 5 = very high)

3. How does your organization define ES? How did your organization come to generate/adopt this definition? Does your organization have a commitment statement for ES? Where would it be recorded?

a. [content analysis - commitment statement: does it include items from CSA 4.2.2.?]

4. Explain how ES is incorporated into your organization, from your perspective as the [job title]

If participant mentions any of the following items from the CSA and/or SSET, ask for additional information:
a. ES team
b. leadership
c. representation from all departments
d. performance indicators
e. energy use (verify with observation; communication with content analysis)
f. water conservation/use (verify with observation; communication with content analysis)
g. managing consumption and waste (verify with observation; communication with content analysis)
h. indoor and outdoor air quality management (verify with observation; communication with content analysis)
i. site restoration plan (verify with observation; communication with content analysis)
j. supply chain (verify with observation; communication with content analysis)
k. transportation (verify with observation; communication with content analysis)
l. food/beverage and catering (verify with observation; communication with content analysis)

5. Who are the internal stakeholders for your organization?

6. Who are the external stakeholders for your organization?

7. To what extent are stakeholder relations influencing ES initiatives? What are the ways in which stakeholders influence ES initiatives?

8. In what ways is ES communicated to internal stakeholders?

9. In what ways is ES communicated to external stakeholders?

10. Explain the process by which ES came to be incorporated into golf course operations.

If participant mentions any of the following items from the CSA and/or SSET, ask for additional information:
a. assessment of environmental impacts
b. legal obligations
c. public pressure

11. What would you consider to be the greatest challenges you and/or the Club have faced when implementing ES into operations? 